AQUATIC CONSERVATION: MARINE AND FRESHWATER ECOSYSTEMS

Aquatic Conserv: Mar. Freshw. Ecosyst. (in press)

Published online in Wiley InterScience

(www.interscience.wiley.com). DOI: $10.1002 /$ aqc.629

\title{
Assessing East African trade in seahorse species as a basis for conservation under international controls
}

\author{
JANA M. MCPHERSON ${ }^{1}$ and AMANDA C.J. VINCENT* \\ Project Seahorse, Department of Biology, McGill University, Montréal, Québec H3A 1B1, Canada
}

\begin{abstract}
1. Seahorses (Hippocampus spp.), many of which are listed as Vulnerable or Endangered on the IUCN Red List, are traded worldwide as souvenirs, aquarium fish and, primarily, for use in traditional medicines. Given concern over the sustainability of this trade, the genus was added to Appendix II of the Convention on International Trade in Endangered Species of Wild Fauna and Flora (CITES) in May 2004.

2. This paper reports findings of the first ever survey of seahorse trade in Africa, conducted in Kenya and Tanzania in May and June 2000.

3. Seahorse trade in Kenya was found to be negligible, with approximately 10 live seahorses exported as aquarium fish annually. Until 1998, however, Kenya may have imported somewhere from 1 to $2.3 \mathrm{t}$ of dried seahorses annually from Tanzania for re-export to Asian medicine markets. Seahorse trade in Tanzania remained substantial, with at least $630-930 \mathrm{~kg}$ of dried seahorse exported directly to Asia each year.

4. Accounts of declines in seahorse availability and seahorse size, although few in number, could be early warning signs that wild populations are suffering, at least locally. Close monitoring of future developments in the trade will be essential to allow for timely conservation action as and when necessary, and would contribute to our understanding of the ecological and economical implications of small-scale, non-food fisheries.

Copyright (C) 2004 John Wiley \& Sons, Ltd.
\end{abstract}

KEY WORDS: Hippocampus spp.; non-food fisheries; seahorse trade; bycatch; CITES

\section{INTRODUCTION}

Seahorses (Hippocampus spp.) came under the remit of the Convention on International Trade in Endangered Species of Wild Fauna and Flora (CITES) on 15 May 2004. The decision to list the genus on Appendix II of the convention was taken at the 12th Conference of the Parties in November 2002 (CITES, 2002b) and places seahorses among the first commercially important, fully marine fishes to be listed on CITES. A listing on Appendix II requires Parties to the Convention (165 countries) to monitor

*Correspondence to: A.C.J. Vincent, Project Seahorse, Fisheries Centre, The University of British Columbia, 2204 Main Mall, Vancouver, British Columbia V6T 1Z4, Canada. E-mail: a.vincent@fisheries.ubc.ca

${ }^{1}$ Current address: Department of Zoology, University of Oxford, South Parks Road, Oxford OX1 3PS, UK. 
international trade of the species through export permits. Moreover, exporting countries are obliged to ensure that their trade is not detrimental to the species' survival in the wild. Given the scarcity of information on and controls over seahorse fisheries, Parties have concerns about how to determine the impact of trade on wild populations (CITES, 2002a). It is thus critical that the international community gain a better understanding of seahorse exploitation globally as soon as possible.

Seahorses are traded worldwide for use in traditional medicines, as aquarium pets and as curios. Initial surveys of this trade in 1993 and 1995 established that the market for seahorses was very large, economically important, and threatening wild seahorse populations (Vincent, 1996). At least 20 million seahorses were traded in 1995, and the number of countries known to be involved in the trade, then 32 (Vincent, 1996), has since risen to at least 75 (Vincent and Perry, in preparation).

The vast majority of seahorses traded are used in traditional Chinese medicine and its derivatives. Treatments containing seahorses are thought to alleviate a range of ailments, including respiratory disorders (such as asthma), sexual dysfunctions (such as impotence), and general lethargy and pains. In addition, several hundred thousand live seahorses each year are taken for home and public aquaria, largely in Europe and North America, and similar numbers are sold dried as souvenirs and curiosities (Vincent, 1996).

The trade in seahorses involves many fishers and consumers, each of whom typically catches or buys relatively few animals. In some parts of the world, small-scale fishers directly target seahorses, sometimes obtaining the majority of their income from these fish. Most seahorses in trade are, however, extracted from incidental bycatch in shrimp trawls and other indiscriminate fishing gear. The largest net exporting countries in 1995 were India, the Philippines, Thailand and Vietnam, and the largest net importers were mainland China, Hong Kong SAR and Taiwan (Vincent, 1996).

The biology of seahorses renders them particularly vulnerable to habitat loss and overexploitation. Their shallow coastal habitats - seagrass beds, mangroves and coral reefs - are amongst the most threatened habitats in the world. Their general fidelity to their mates, limited mobility and site fidelity hamper repairing if one partner is lost and restrict the rate at which seahorses recolonize depleted areas (Foster and Vincent, in press). Moreover, extensive parental care by males, coupled with low reproductive rates, precludes rapid recovery of overexploited populations (Foster and Vincent, in press).

Current rates of extraction appear to have serious effects on wild seahorse populations. Many seahorse species (9 of 33) are listed on the IUCN Red List as Vulnerable, and one African species, Hippocampus capensis, is considered to be Endangered because of its very small geographic range, which is suffering habitat damage (IUCN, 2003). All other seahorse species are considered Data Deficient. Fishers and traders in key areas of exploitation in Southeast Asia and India reported declines in seahorse catches in the order of 15-50\% between 1990 and 1995 (Vincent, 1996). In most regions, however, seahorse ecology is little known, and the consequences of exploitation have to be deduced from limited information.

Further surveys of the seahorse trade were initiated in 1999 and 2000 to assess developments in the trade and include areas of the world not previously covered. This paper reports findings from research conducted in Kenya and Tanzania in May and June 2000 - the first ever seahorse trade survey on the African continent. Compilation of cursory information on trade in other African countries is under way (McPherson and Vincent, in preparation), but this work in East Africa represents the only detailed assessment to date of African seahorse fisheries and consumption.

\section{METHODS AND DEFINITIONS}

\section{Study animals}

Seahorses are teleost fishes in the family Syngnathidae, along with pipefishes, pipehorses and seadragons. A recent taxonomic revision describes 32 species, all in the genus Hippocampus (Lourie et al., 1999). Many 
new seahorse species have recently been proposed, at least some of which likely are genetically valid (Kuiter, 2000, 2001; Lourie and Randall, 2003). Few species have been studied in detail, and even fewer in the wild. A summary of what is known about seahorses' life-history traits and behavioural characteristics can be found in Foster and Vincent (in press).

Four species have previously been recorded in East Africa, none of them yet studied methodically (Foster and Vincent, in press). Among them, Hippocampus histrix and Hippocampus kelloggi are relatively cosmopolitan; specimens of these species have been collected at numerous locations in the Indian Ocean, as well as in the Pacific. The distributions of Hippocampus borboniensis and Hippocampus camelopardalis, in contrast, are limited to Indian Ocean waters along Africa and its offshore islands (Lourie et al., 1999).

During this study, a fifth species, Hippocampus fuscus, was encountered in East Africa. This species was previously known from the Red Sea and Sri Lanka, with probable records also from Madagascar, Mauritius, La Réunion, and South Africa (Lourie et al., 1999). Under laboratory conditions, H. fuscus is a diurnal species whose adults form faithful pair-bonds for breeding, as with most seahorse species studied to date (Vincent, 1990; Vincent and Sadler, 1995). What little is known about each of the five species' habitat associations in situ is shown in Table 1.

The dearth of information on the five East African species prescribes reliance on generalities established in a recent review of seahorse biology and ecology (Foster and Vincent, in press). Seahorses generally feed on live prey, primarily amphipods, and rely heavily on camouflage both to ambush prey and to avoid predators. Most species are monogamous. Their home ranges tend to be small and their mobility low, although adults of some species may migrate seasonally (Foster and Vincent, in press). Seahorse density tends to be low and patchy. Surveys of the South African endemic H. capensis, for example, recorded an overall mean density of $0.0089 \mathrm{~m}^{-2}$ during randomized transect surveys that covered a total of $4920 \mathrm{~m}^{2}$, but mean density reached $0.22 \mathrm{~m}^{-2}$ in a focal study grid of $100 \mathrm{~m}^{2}$ (Bell et al., 2003). In situ studies of other species recorded mean densities of $0-0.51 \mathrm{~m}^{-2}$, but local densities of up to $10 \mathrm{~m}^{-2}$ (Foster and Vincent, in press).

The relative desirability of East African species in the medicinal, aquarium and curio trades is difficult to judge. Customers of traditional Chinese medicine tend to prefer smooth and large seahorses (Vincent, 1996), which would render $H$. kelloggi a prime target, $H$. fuscus and $H$. camelopardalis secondary targets (both smooth but medium sized), and H. borboniensis and H. histrix least desirable (both medium sized but spiny, particularly $H$. histrix). $H$. histrix, however, is specifically listed as a medical ingredient in traditional Chinese Pharmacopoeias (Vincent, 1996) - though identification in such manuals is commonly flawed - and its striking appearance might render it popular among aquarium hobbyists and souvenir hunters.

Table 1. Known habitat associations of the five seahorse species present in East Africa. Records on the habitats and depths in which each species has been observed were gleaned from Choo and Liew (2003), Golani and Fine (2002), Kuiter (2000), Kuiter and Debelius (1994), Lourie et al. (1999), and Lowe (1843)

\begin{tabular}{lll}
\hline Species & Habitat association & Depth \\
\hline Hippocampus borboniensis & Seagrass, soft bottom, sponge & $5-60 \mathrm{~m}$ \\
Hippocampus camelopardalis & Seagrass beds, algal beds and shallow reefs & Up to $45 \mathrm{~m}$ \\
Hippocampus fuscus & $\begin{array}{l}\text { Calm, shallow, protected waters in lagoons, } \\
\text { bays and harbours; eelgrass beds, the edges of algal reefs }\end{array}$ & $0.5-10 \mathrm{~m}$ \\
& $\begin{array}{l}\text { and seagrass beds, stones, gravel, artificial structures } \\
\text { Hippocampus histrix }\end{array}$ & Ueagrass beds, weedy rocky reefs, \\
& $\begin{array}{l}\text { sponges and seasquirts in areas of sparse or no seagrass, } \\
\text { soft bottoms with soft corals and sponges }\end{array}$ & \\
Hippocampus kelloggi & Soft bottoms, associated with gorgonians and sea whips & Up to $90 \mathrm{~m}$ \\
\hline
\end{tabular}




\section{Surveys and interviews}

Data on seahorse trade in East Africa were gathered during field research in Kenya and Tanzania in May and June 2000. Thirteen sites were visited in Kenya, and 22 in Tanzania (Figure 1). Interviews were conducted with 221 people, and a further 13 were consulted in writing (Table 2). Customs data were also examined, along with reports on local fisheries and the status of local marine resources.

Interviews were generally conducted in Kiswahili (via a local assistant) without any formal structure. Each interview sought to obtain information on the prevalent use of seahorses, past and present trade volumes, values, demand, supply and availability. Where appropriate, discussions also addressed ecological questions. Information was cross-checked by rephrasing the same question at different stages during the interview and by asking the same question of people at different levels of the trade.

The identities of respondents are only revealed where this is judged neither to jeopardize the person or agency involved, nor to precipitate difficulties for future conservation research. Often, references to 'a fisher' or 'the exporter' must suffice. Participants in the seahorse trade are referred to by 'level' in this paper, where fishers - the first to handle seahorses - are level 1 and their immediate buyers are level 2. Thereafter, levels increase with each successive buyer up to the exporter and clients abroad. Often, people work at several levels simultaneously: someone who fishes seahorses but also buys them from other fishers, for example, operates at both levels 1 and 2.

\section{Estimates of species' occurrence and seahorse abundance}

Because seahorse species look superficially similar, most respondents were unaware that seahorses comprised several species. Fishers and divers, however, were generally able to provide an estimate of seahorse size and indicate whether seahorses in their region had prominent spines or not. In addition, some fishers and traders provided dried specimens for identification ( 25 specimens in total). This information was used to deduce likely areas of occurrence for each species.

To gain an understanding of the relative abundance of seahorses along East Africa's coast (all species combined), fishers, divers and other respondents who encountered seahorses in the wild were asked to provide estimates of the frequency of encounter. Among fishers, this involved a description of their fishing technique, an estimate of the number of times seahorses were sighted (under water or caught in fishing gear) per unit of time, and the number of individuals per sighting. Respondents with experience in more than one region along the coast were also asked for a subjective comparison of seahorse abundance in these regions. Corresponding in situ densities were impossible to deduce from respondents' observations, given the many confounding factors (e.g. experience, fishing gear, timing, season and locality of sightings).

\section{Trade calculations}

Volume estimates are concerned with amounts consumed (throughput) rather than amounts held (standing stock) at each trade level, since only the former provide information on the rate of exploitation. Volume estimates in this study were derived primarily from fishers' and buyers' memories, with consequent inherent imprecision. Information on sales was recorded in the units used by the respondents and later converted to kilograms or seahorses per year; units used by respondents included seahorses per day, boxes per bamvua (lunar period important for fishing, approximately one fortnight), or kilograms per season. Where sales prices were given, these were recorded in the currency used by the correspondent and converted to US dollars based on currency conversion rates listed in Table 3 . The validity of trade estimates was weighted by the reliability of the respondent, based on their answers to control questions with known answers.

Rough calculations of total consumption at any given trade level came from multiplying throughput estimates and the number of people at that particular level. Comparison across levels allowed some verification of these estimates, but it is fully recognized that extrapolations based on a limited number of 


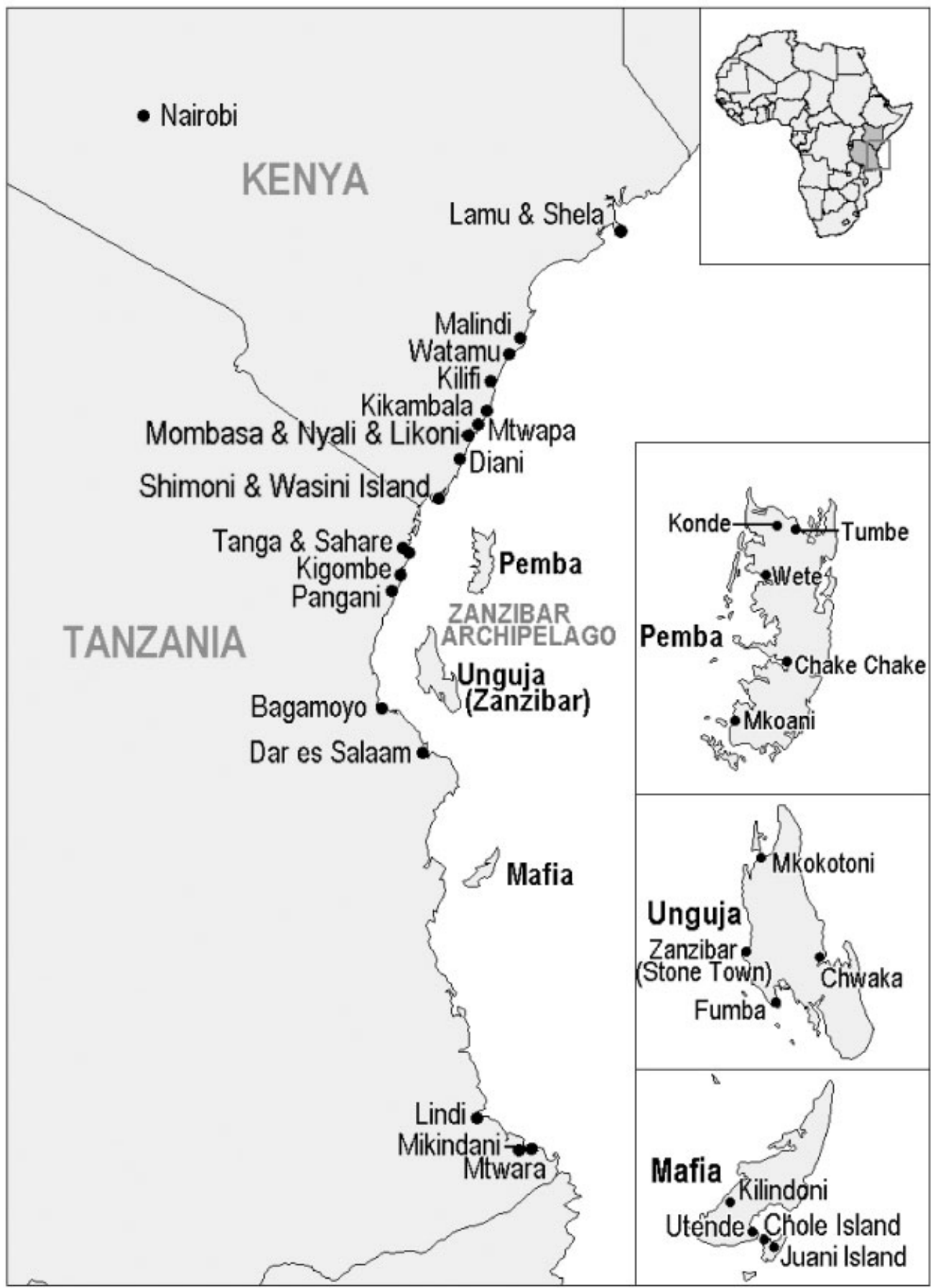

Figure 1. Sites surveyed in East Africa during May and June 2000. 
Table 2. The number and background of respondents consulted during surveys in Kenya and Tanzania in May and June 2000

\begin{tabular}{lccr}
\hline Respondent background & Kenya & Tanzania & Total \\
\hline Academic & 2 & 3 & 5 \\
Aquarist & 3 & 1 & 4 \\
Aquarium fisher & 4 & 0 & 4 \\
Artisanal fisher & 12 & 72 & 84 \\
Commercial fisher & 0 & 2 & 2 \\
Diver/snorkeller & 10 & 2 & 12 \\
Government official & 17 & 13 & 30 \\
Healer & 1 & 8 & 9 \\
NGO employee & 11 & 16 & 27 \\
Trader of aquarium fishes & 13 & 25 & 15 \\
Trader of marine products & 7 & 6 & 32 \\
Other & 4 & 150 & 10 \\
Total & 84 & & 234 \\
\hline
\end{tabular}

Table 3. Currency conversion rates

\begin{tabular}{ll}
\hline Period $^{\mathrm{a}}$ & Rate \\
\hline 2000 & $1 \mathrm{TSh}=0.00130 \mathrm{US \$}$ \\
1998 & $1 \mathrm{KSh}=0.01420$ US\$ \\
1997 & $1 \mathrm{TSh}=0.00150$ US\$ \\
& $1 \mathrm{TSh}=0.00165$ US\$ \\
1995 & $1 \mathrm{KSh}=0.01825$ US\$ \\
1994 & $1 \mathrm{TSh}=0.00170$ US\$ \\
1990 & $1 \mathrm{TSh}=0.00200$ US\$ \\
1975 & $1 \mathrm{TSh}=0.05000$ US\$ \\
\hline
\end{tabular}

${ }^{a}$ Exchange rates for former years were taken from Country Profile Tanzania 1999-2000, 1994-1995 and 1986-1987. Economist Intelligence Unit: London.

interviews can provide only a crude approximation of total trade. Volume estimates are likely to represent a minimum and must, therefore, be treated with the appropriate caution, but they are thought to be helpful indices for future evaluation.

\section{RESULTS AND DISCUSSION}

\section{Species and distributions}

All four seahorse species previously documented to occur in the region were found during the study: $H$. borboniensis, H. camelopardalis, H. histrix and H. kelloggi (all previously recorded in Zanzibar; Lourie et al., 1999). In addition, H. fuscus was encountered, for which the nearest previous record was Madagascar. Only $H$. histrix was seen in both Kenya and Tanzania. All other species were found only in Tanzania, although respondents' accounts suggest that $H$. camelopardalis and possibly $H$. fuscus and $H$. kelloggi also occurred in Kenya (Figure 2).

Seahorses apparently occurred all along the mainland coast of Kenya and Tanzania, as well as in the Zanzibar and Mafia archipelagos. They were considered rare by fishers and would-be traders in Kenya, 


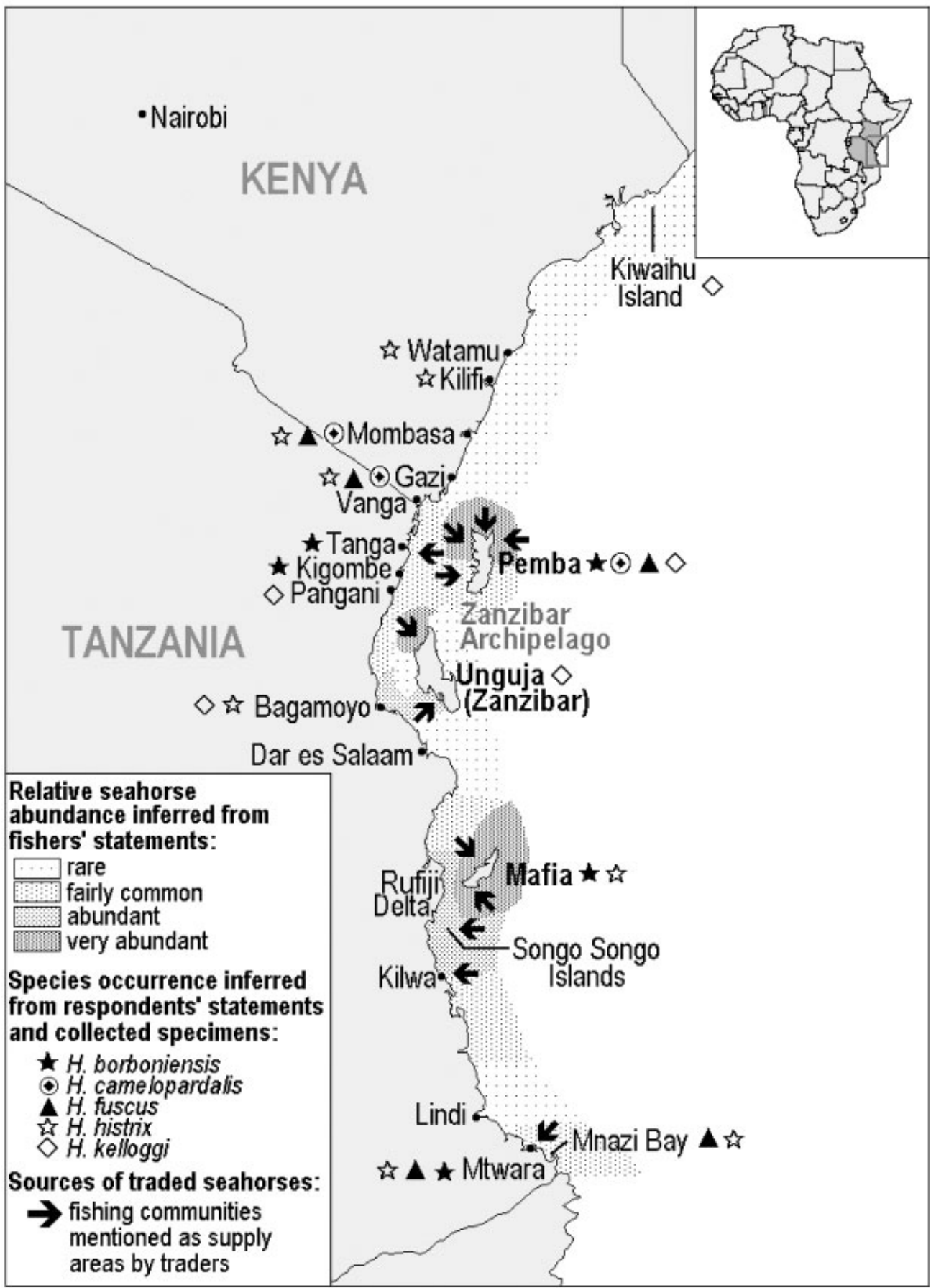

Figure 2. Species occurrence and relative abundance of seahorses in East Africa, with the areas supplying seahorses to Tanzania's dried seahorse trade indicated by arrows. 
with the possible exceptions of Kilifi Creek and Vanga, where seahorses were reportedly slightly more abundant. In Tanzania, these fish seemed more common: fishers and traders gave the impression that seahorses were (1) rare off Dar es Salaam, Lindi and most of Unguja; (2) fairly common in northern Tanzania (Tanga, Kigombe, Pangani), Mtwara and southern Pemba; (3) abundant in Bagamoyo, the Rufiji Delta, and Unguja's Menai Bay; and (4) very abundant in most of northern Pemba, off Mkokotoni in the north of Unguja and in Mafia, particularly Mafia's western side (Figure 2).

More than one species of seahorse commonly occurred in the same area, judging from the many fishers who mentioned the presence of both spiny (potentially $H$. borboniensis or $H$. histrix) and non-spiny $(H$. camelopardalis, H. fuscus, or H. kelloggi) seahorses in their fishing grounds. Researchers of Frontier, a nongovernmental organization (NGO) conducting base-line surveys of Tanzania's habitats, confirmed that two species co-existed in Mtwara Bay (H. histrix and a smoother species; Davide Molon, in litteris, 7 July 2000).

Respondents most frequently associated seahorses with marine vegetation in shallow water $(<10 \mathrm{~m})$, particularly mwani, which fishers described as a tall, grass-like plant growing at low density. Seahorses were also strongly associated with corals and rocks, or a mix of corals and vegetation, and occurred among mangroves, on bare sand and in floating weeds. Many respondents reported that seahorses occurred near small islands. In Kenya, there was frequent mention of seahorses' preference for sediment-laden, murky waters and estuaries. Such reports were unlikely to reflect a bias in fishing practice because most fishing occurred in clear water (outside the rainy seasons) and on reefs.

\section{Local use of seahorses}

Local use of seahorses in East Africa was limited, with occasional use for decorative purposes, as fishing souvenirs, as aquarium pets, by traditional healers and as curios. Fishers in southern Kenya and along Tanzania's entire coastline sporadically dried and used seahorses as necklaces, key rings, house decorations or simply as fishing mementos. The practice was said to be rare and limited to children and young men. A fisher near Bagamoyo had nevertheless managed to turn it into a small business by painting the seahorses and selling them to locals for up to TSh700 (US\$0.90) each. A few seahorses found their way into private and public aquaria; these were obtained directly from fishers, or sometimes the aquarists collected them from the wild themselves.

No traditional healer questioned $(n=9)$ knew of any use for seahorses. Neither was their use reported during more extensive surveys of African traditional medicine practices (Marshall, 1998). However, traders in Dar es Salaam occasionally sold seahorses to traditional healers from as far away as Arusha and Mwanza. According to the National Chairman of the Tanzania Traditional Healers Association, the use of animals in traditional medicine was often associated with sorcery and, therefore, kept secret. One fisher did report on the use of seahorses by his colleagues in Fukuchani, northern Unguja. Disappointed with their catch, they sought help from a traditional doctor. He ordered them to find a seahorse, burn it, mix its ashes with a plant concoction he provided and sprinkle the resulting liquid over their gear. This would apparently rid the gear of bad spells and attract fish.

Four curio traders in Dar es Salaam, who included dried, unvarnished seahorses among their stock of seashells, desiccated sea stars and puffer fish, indicated that tourists occasionally bought one or two dried seahorses for educational purposes or as souvenirs. Respondents' suggestions that curio traders on Pemba Island and Unguja Island also sold seahorses could not be substantiated.

\section{Live seahorse trade}

In Kenya, seahorses were exported as aquarium fish in negligible numbers. No live seahorse trade was encountered in Tanzania.

The ornamental fish trade in Kenya dates back to the 1960s, with five exporters operating in 2000. Ornamental fish were target-caught with handheld nets by fishers using scuba or snorkel. These aquarium 
fishers generally supplied a single exporter, who in turn provided their gear, boats and transport. The aquarium fishers caught seahorses occasionally, but did not target them specifically for both practical and economical reasons, according to respondents:

- Fishing effort concentrated around reefs, whereas seahorses were found in seagrass beds in murky creeks.

- Exporters did not advertise seahorses to clients and discouraged their catch, because during shipping these fish required a lot of space and suffered high mortality $(20 \%)$.

- Seahorses fetched low prices abroad, meaning that exporters earned little profit if they compensated Kenyan fishers adequately for what was locally a rare and discrete catch. One exporter paid his fishers KSh100-150 (US\$1.42-2.13) per seahorse, but received at most US\$3.00 for them abroad. For other fish, e.g. Arothron citrinellus, exporters paid fishers KSh500 (US\$7.10) yet received up to US\$65 abroad. Low international prices for seahorses, in the view of one exporter, resulted from ample supply by other countries, where seahorses were plentiful and 'caught with poison'.

Respondents' information suggested that fewer than 10 seahorses were traded each year. Two companies exported any seahorses they obtained to Europe, whereas another sold them to the company's former owner as pets.

Existing official sources corroborated respondents' suggestions that the live seahorse trade in Kenya was negligible. Detailed records of export consignments provided to the Kenyan Department of Fisheries by ornamental fish dealers listed no seahorses between 1968 and May 2000 (Kenyan Department of Fisheries, unpublished data). European Community Customs records, which have recorded syngnathid trade since 1997, registered only three live Kenyan seahorses between then and 2001, imported to Germany for commercial purposes in 1999 and 2000 (European Community, unpublished data).

\section{Dried seahorse trade}

\section{Overview}

Tanzania dominated the dried seahorse trade in East Africa. No such dried trade occurred in Kenya in 2000. Until 1998, however, Kenya may have imported between 1 and $2.3 \mathrm{t}$ of dried seahorses from Tanzania annually for re-export to Asia. Tanzania continued to trade large quantities (634-937 kg) of dried seahorses in 2000, sourced primarily in its own waters, but with some imported from Mozambique. Within Tanzania, Pemba Island emerged as a major source, but traders also obtained supplies from Mafia, Unguja, the Songo Songo Islands and various locations along the mainland coast (Figure 2). All five of the region's seahorse species were exploited for the trade, but H. fuscus and H. borboniensis were most common in traders' stocks. Exports were generally routed through the capital, Dar es Salaam, although some possibly left the country from Zanzibar (Figure 3). Destinations included Hong Kong SAR, Taiwan, mainland China and, potentially, the USA.

\section{History}

The dried seahorse trade in Tanzania dates back to at least 1975, according to a major trader (level 3-4) who began operating then. Other African countries, such as Nigeria, apparently only joined the trade in the 1990s (McPherson and Vincent, in preparation). Perhaps Tanzania's links with China, one of its major aid providers (Ping, 1999), explain its early entry into the trade; Chinese aid workers may have alerted Tanzanians to the fact that dried seahorses were a sought-after commodity in Asia.

Seahorse trade between Kenya and Tanzania occurred at least as early as 1985, when a Tanzanian exporter (level 2-4) conducted business transactions with a client from Hong Kong in the Kenyan capital 


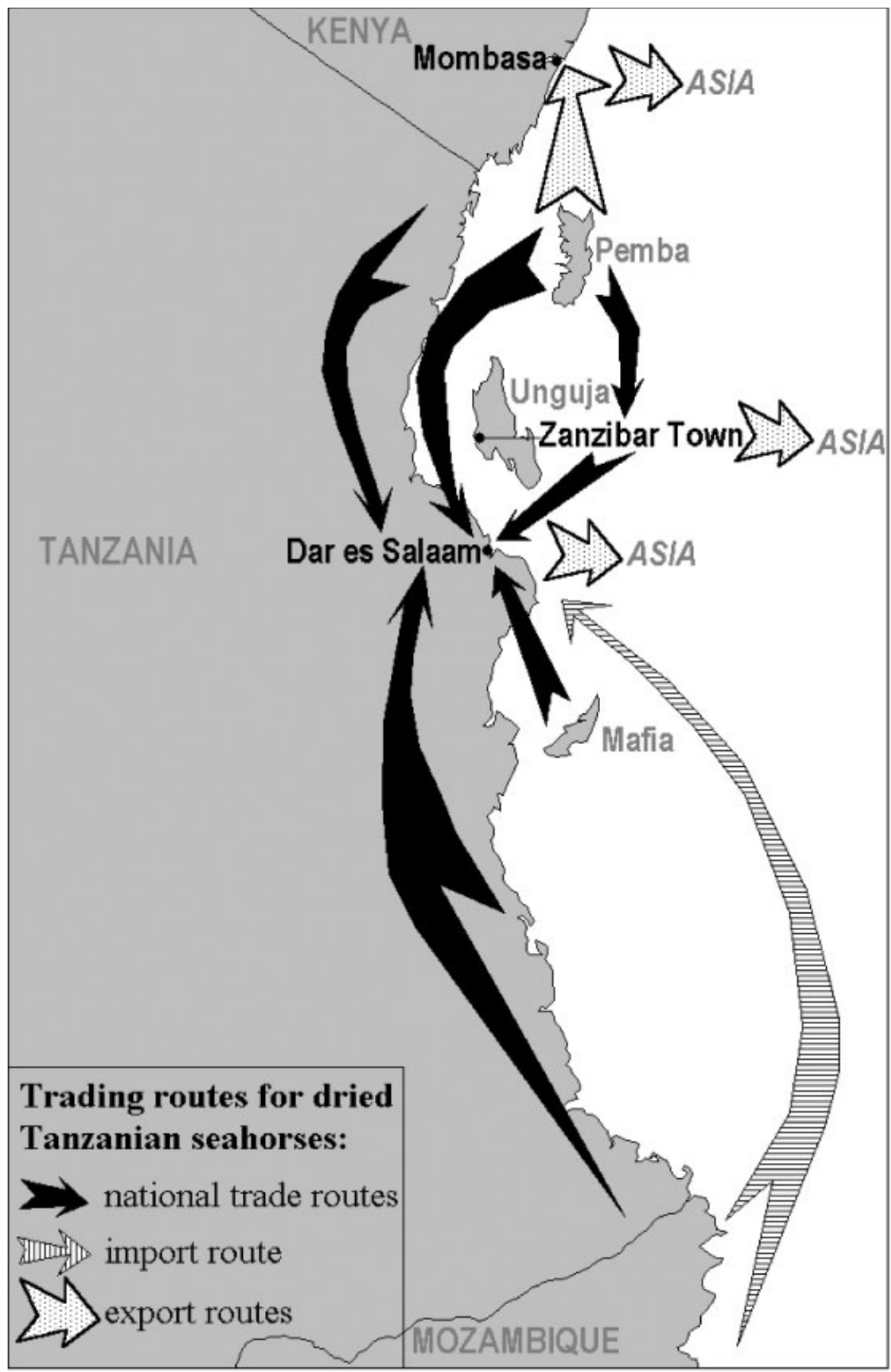

Figure 3. Reported trade routes for dried Tanzanian seahorses. 
Nairobi, because unfavourable exchange policies in his own country would have made trade less profitable there.

\section{Structure}

The majority of seahorses in Tanzania's trade originated from artisanal fishers' bycatch. All along the coast, seahorses were caught incidentally in a variety of fishing gear, particularly beach seines and purse seines. Commercial trawling vessels also landed a very few seahorses: only one trader (level 2-4) listed these trawlers among his sources, estimating that each vessel supplied 10-15 seahorses per month. In 2000, 15-20 trawlers operated in Tanzanian waters, but only some retained seahorses for sale. The current study identified only one targeted seahorse fishery, which reportedly occurred in Tumbuju on Mafia Island in the early 1990s. According to an old fisher who had taken part, seahorses had been targeted at night using kavago, a form of seining.

The desiccation process involved simply laying or hanging seahorses in the sun. As an alternative, during the rainy season, one former seahorse fisher recalled drying seahorses on wire mesh above charcoal embers. Inadequate desiccation or storage incurred damage by insects. Traders at all levels, therefore, faced the challenge of selling their stock before it deteriorated or became worthless.

Traded seahorses passed through up to four trade levels before entering foreign hands (Figure 4). Fishers (level 1) generally sold seahorses to a local agent. Local agents (level 2) purchased seahorses only from their own fishing community. They generally sold to one or two regular buyers, usually itinerant middle dealers, from whom they received a baseline salary and cash advances for seahorse purchases. The itinerant middle dealers (level 3) transported seahorses from source locations to the marketing centre (usually Dar es Salaam), where they passed them either to exporters (level 4) or to traders (level 4) who sold to foreigners locally (level 5).

Foreigners buying seahorses locally (level 5) included both professional and amateur traders. Professional traders are here defined as those foreigners who visited Tanzania specifically to purchase seahorses and other marine-products (e.g. sea cucumbers, shark fins) for the Asian medicine or delicacy market. According to a major level 3-4 trader in Dar es Salaam, these entrepreneurs contacted their Tanzanian business partners prior to arrival, specifying quantity, quality and price of products to be supplied. In contrast, the amateur traders were 'Chinese' people (likely to include any East-Asian-looking

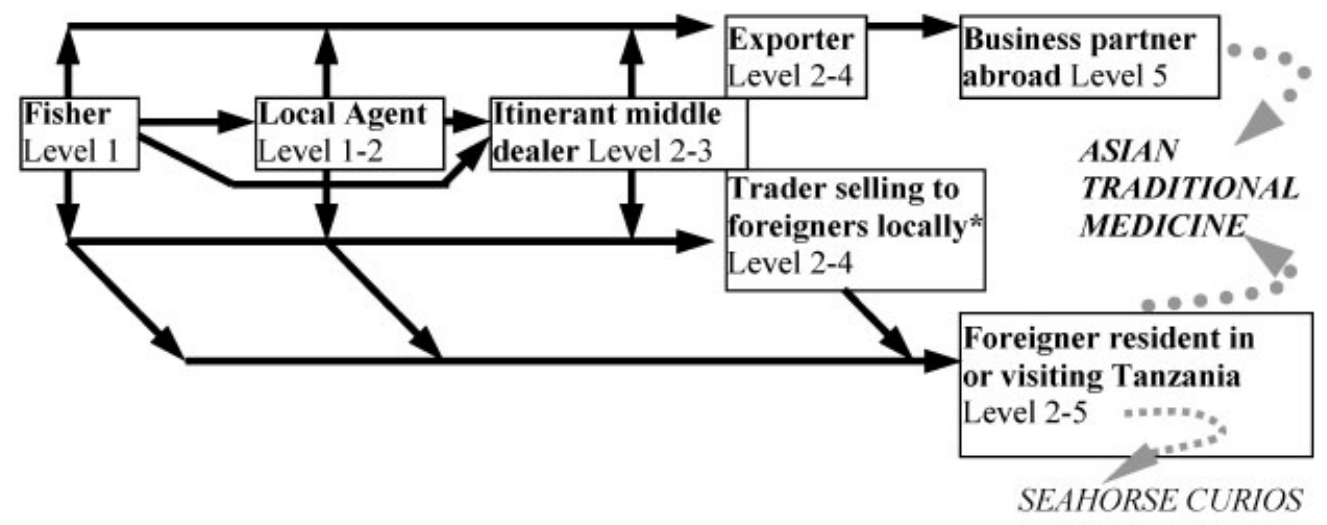

LEVEL 1 LEVEL 2 LEVEL 3 LEVEL 4 LEVEL 5

*Includes both curio traders and traders exclusively targeting the Asian medicine market

Figure 4. Agents in Tanzania's dried seahorse trade and their interactions. 
person) visiting or resident in Tanzania as doctors, engineers or aid workers, who - according to three fishers in Pemba, one fisher in Tanga and five traders (level 2-4) in Dar es Salaam - bought seahorses in bulk from local traders or fishers before returning to Asia. Tanzanian and foreign traders of all levels occasionally skipped intermediate levels, and operated at multiple levels themselves (Figure 4).

\section{Value}

Seahorse prices were highly variable in place and time; where trade was a recent phenomenon, prices were low (Table 4). One trader (level 2-3) suggested that higher level traders (level 4) fostered ignorance among their suppliers about the destiny of traded seahorses so as to maintain low prices. Indeed, none of the fishers aware of the trade $(n=23)$ knew of the ultimate use of traded seahorses. Among level 2-3 traders $(n=7)$, only two understood that dried seahorses were destined for Asia; a third trader believed they were primarily sold to tourists as curios.

At all trade levels, seahorse-derived earnings provided a welcome bonus, but made only a small contribution to fishers' and traders' incomes. No agents involved in the seahorse trade specialized in these

Table 4. Comparison of the value of dried seahorses over place, time and trade level

\begin{tabular}{|c|c|c|c|c|c|}
\hline \multirow[t]{2}{*}{ Location } & \multirow[t]{2}{*}{ Year } & \multicolumn{4}{|c|}{ Payment (in US\$) received by } \\
\hline & & $\begin{array}{l}\text { Fishers } \\
\text { (level 1) }\end{array}$ & $\begin{array}{l}\text { Local } \\
\text { agents } \\
\text { (level 2) }\end{array}$ & $\begin{array}{l}\text { Middle } \\
\text { dealers } \\
\text { (level 2-3) }\end{array}$ & $\begin{array}{l}\text { Exporters } \\
\& \text { traders } \\
\text { selling to } \\
\text { foreigners } \\
\text { locally (level 2-4) }\end{array}$ \\
\hline $\begin{array}{l}\text { Per seahorse } \\
\text { Dar es Salaam }^{\text {a }}\end{array}$ & $\begin{array}{l}2000 \\
1995 \\
1994 \\
1975\end{array}$ & $0.39-1.56$ & & $\begin{array}{l}0.20-0.91 \\
0.26-0.35 \\
0.20\end{array}$ & $\begin{array}{l}0.52-7.80 \\
0.07-0.14\end{array}$ \\
\hline Pemba & $\begin{array}{l}2000 \\
1994\end{array}$ & $\begin{array}{l}0.07-0.20 \\
0.10\end{array}$ & $0.46-0.52$ & & \\
\hline $\begin{array}{l}\text { Tanga } \\
\text { Mafia } \\
\text { Unspecified }\end{array}$ & $\begin{array}{l}2000 \\
1990 \\
2000\end{array}$ & $\begin{array}{l}0.04 \\
0.001 \\
0.10-1.30\end{array}$ & $0.65-1.04$ & & \\
\hline $\begin{array}{l}\text { Per kilogram } \\
\text { Dar es Salaam }\end{array}$ & $\begin{array}{l}2000 \\
1998\end{array}$ & & & $\begin{array}{l}104.00-130.00 \\
37.61\end{array}$ & $80.00-300.00^{\mathrm{b}}$ \\
\hline Pemba & $\begin{array}{l}2000 \\
1996-1997\end{array}$ & & $\begin{array}{l}16.90 \\
0.33\end{array}$ & & $0.73^{\mathrm{c}}$ \\
\hline Unguja & $\begin{array}{l}2000 \\
1994-1995\end{array}$ & $\begin{array}{l}18.18 \\
12.18^{\mathrm{d}}\end{array}$ & 22.10 & & $20.00-30.00^{\mathrm{d}}$ \\
\hline
\end{tabular}

\footnotetext{
${ }^{a}$ Middle dealers selling in Dar es Salaam obtained supplies cheaply elsewhere, which may explain why they received less per seahorse than fishers.

${ }^{\mathrm{b}}$ Export to Hong Kong. Exact price varied with seahorse size: grade I (100-200 seahorses/kg) US\$300; grade II (200-400 seahorses/kg) US\$130/kg; grade IV (600 seahorses $/ \mathrm{kg})$ US\$80-140 in low and high season respectively.

${ }^{\mathrm{c}}$ Export to Mombasa, Kenya.

${ }^{\mathrm{d}}$ Unguja fishers were unwilling to provide the exporter with seahorses for the price offered, so these are quoted prices only; no trade occurred.
} 
animals. Fishers (level $1 ; n=15$ ) reported that they would glean seahorses from their bycatch when buyers were around, but were rarely willing to target seahorses specifically. Their seahorse-derived earnings were described by one fisher as 'cigarette money'. Local agents (level 2) tended to be fishers themselves or fishmongers for whom seahorses were a sideline. Traders at higher levels (level 3-4) had diverse business portfolios, although most specialized in marine-products. Among five higher level traders who provided an estimate, four felt that seahorse trading constituted $10 \%$ or less of their income; one estimated $25 \%$.

\section{Volumes formerly traded between Tanzania and Kenya}

Kenya did not, apparently, exploit its own seahorses for the dried trade, but had traded Tanzanian seahorses in the past. Three of six marine-products exporters interviewed in Mombasa (Kenya) explained that seahorses were too rare in Kenya to make their trade a viable business; one had reached this conclusion after careful investigation in response to an order from Singapore. Three Tanzanian respondents reported, however, that dried seahorses had been taken to Mombasa from Pemba Island (Tanzania) between 1995 and 1998. Between them, they named three fishing communities in Pemba and three marine-products dealers in Mombasa who had been involved in this trade.

The one informant who had taken part in the trade himself, acting as middle dealer (level 3), reported that he had shipped three sacks of dried seahorses to his client in Mombasa on two consecutive fortnights, each sack weighing $60-90 \mathrm{~kg}$. On the following fortnight, he made a final shipment of $30 \mathrm{~kg}$ and then discontinued trade due to dwindling supplies. In total, therefore, he had reportedly exported $390-570 \mathrm{~kg}$ of dried seahorses in 6 weeks. Each kilogram had sold for KSh40 (then US\$0.73) in Mombasa. His estimates, however, are questionable: at an average dry weight of $2.4 \mathrm{~g}$ per Pemban seahorse (range 0.7 to $7.4 \mathrm{~g}$; 16 specimens), $90 \mathrm{~kg}$ would comprise 37500 seahorses; a single sack is unlikely to hold this many dried seahorses. In contrast, $30 \mathrm{~kg}$ (12 500 seahorses) may fit into one very large sack. Moreover, $30 \mathrm{~kg}$ constitutes a plausible fortnightly catch in northern Pemba. According to information provided by respondents, seahorse abundance in northern Pemba is similar to seahorse abundance near Mafia Island. An old fisher from Tumbuju, Mafia, reported that a target fishery there in the early 1990s fortnightly harvested 13000 31000 seahorses with relative ease (six groups of seine fishers casting their nets one or two evenings per fortnight).

It seems reasonable to assume, therefore, that the three Pemban communities involved in the trade with Mombasa between 1995 and 1998 each exported $30 \mathrm{~kg}$ of dried seahorses per fortnight. Trade may, however, have been seasonal. Eight of 16 Tanzanian traders (level 2-4) suggested that more seahorses were caught and traded during kaskazi, the northeasterly monsoons (around October to February), when weather facilitated drying. If the three Pemban villages restricted seahorse trade to kaskazi, then marineproducts dealers in Mombasa would have imported and re-exported just under $1 \mathrm{t}$ of seahorses each year ( 3 villages $\times 11$ fortnights $\times 30 \mathrm{~kg} /$ fortnight $=990 \mathrm{~kg}$ or 412500 seahorses). If the trade continued all year, however, then these dealers would have imported and re-exported as many as $2.3 \mathrm{t}$ of dried seahorses per annum ( 3 villages $\times 26$ fortnights $\times 30 \mathrm{~kg}$ /fortnight $=2340 \mathrm{~kg}$ or 975000 seahorses). The seahorse trade through Kenya reportedly stopped in 1998 due to dwindling supplies and a lack of convenient transport after weekly ferry operations between Pemba and Mombasa ceased.

\section{Dried seahorse exports from Tanzania in 2000}

Deductions from trade interviews lead to the inference that total annual exports by professional and amateur traders from Tanzania probably exceeded $600 \mathrm{~kg}$, roughly equivalent to 254000 seahorses.

Respondents named at least four operating export traders. Sixteen further merchants exporting related marine-products (sea cucumbers, shark fins, seashells and fish offal) to Asia were listed in 1995 Customs records for mainland Tanzania (excluding Zanzibar). It is probable that many of these merchants were aware of the commercial value of seahorses in Asia, and therefore possibly traded in them. 
Two of the export traders (level 3-4) named by respondents were interviewed; both were trading with business partners in Hong Kong SAR, and Taiwan, and each sold approximately $100 \mathrm{~kg}$ of dried seahorses annually. They were unable to say much about their competition, and apparently were unaware of each other. One, however, estimated that at least four other exporters traded in seahorses. As these may or may not have overlapped with those named by other respondents, a minimum of six to eight export traders were operating in 2000; but there were potentially many more if the merchants listed in mainland customs records and others in Zanzibar also engaged in the trade.

If all traded similar volumes to the two who were interviewed $\left(100 \mathrm{~kg} \mathrm{yr}^{-1}\right)$, then professional traders exported at least $600-800 \mathrm{~kg}$ of dried seahorses from Tanzania each year. At an average weight of $2.36 \mathrm{~g}$ per seahorse $(n=25)$, this corresponds to approximately 254000-339000 seahorses.

In contrast to professional traders, amateur traders apparently relied heavily on the marine curio market in Dar es Salaam for seahorse supplies. Dealers at this market, in turn, received their seahorses from various sources, including Dar es Salaam-based fishers returning from fishing expeditions to Zanzibar or the Mafia Archipelago and middle dealers operating in Pemba and Mafia. One Pemba-based middle dealer (level 2-3) reported that he single-handedly supplied the curio market with 21600 to 24000 seahorses annually. At an average of $2.4 \mathrm{~g}$ per Pemban seahorse $(n=16)$, this equals 51.8 to $57.6 \mathrm{~kg}$ annually and provides a minimum estimate of trade at this market.

Information obtained at the curio market led to three estimates of similar magnitude:

1. The market comprised 40 traders. Four were interviewed and provided information on their own sales volumes, for a first estimated total of 3880-5840 seahorses per annum (Table 5). If the trade of those interviewed was representative of all 40 traders, then the total for the market would have been 39000 58000 seahorses. At an average weight of $2.36 \mathrm{~g}$ per seahorse $(n=25)$, this amounts to $92-137 \mathrm{~kg}$.

2. Apparently, all 40 traders sold seahorses occasionally, but six engaged in the business more consistently. If each of these six sold about 200 seahorses per month (as did trader D in Table 5), then foreign amateur traders obtained at least a second estimated total of $14400(\sim 34 \mathrm{~kg})$ dried seahorses from them each year, plus several hundred more from the other 34 curio traders who occasionally dealt in seahorses.

3. One of the curio traders interviewed provided a third way to estimate total seahorse throughput at this market. He reported that 'Chinese' living in Dar es Salaam visited the market regularly to buy as many seahorses as were available. At least one of these regulars visited daily during the low trading season, and two regulars visited daily from December through to February. Such clients bought at least 50 - but preferably 100 - dried seahorses each visit. Accordingly, East Asian residents purchased at least 22400 dried seahorses at the curio market each year (40weeks@1 buyer $\times 50$ seahorses $\times 7$ days $/$ week + 12 weeks@2 buyers $\times 50$ seahorses $\times 7$ days $/$ week), equivalent to $53 \mathrm{~kg}$.

Table 5. Volumes of dried seahorses traded by four traders (level 2-4) at the marine curio market in Dar es Salaam, Tanzania

\begin{tabular}{llc}
\hline Trader & Sales estimate provided & $\begin{array}{c}\text { Annual total } \\
\text { (no. of seahorses) }\end{array}$ \\
\hline A & $100-200$ seahorses/year & $100-200$ \\
B & $5-30$ seahorses/month & $60-360$ \\
C & $80-120$ seahorses/month in March-November; & $1320-1680$ \\
D & 200 seahorses/month in December-February & $2400-3600$ \\
Total & $200-300$ seahorses/month all year round & $3880-5840$ \\
\hline
\end{tabular}


Between 34 and $137 \mathrm{~kg}$ of dried seahorses, therefore, left the country annually in addition to the 600$800 \mathrm{~kg}$ exported by professional traders.

Few official sources exist to corroborate these volume estimates. Only the USA and Hong Kong SAR official records reported imports from Tanzania. The USA noted the import of 628 dried Tanzanian seahorses, worth US\$36076 in total, between 1996 and 2000 (US Fish and Wildlife Service, unpublished). Their purported value alone (US\$57 per seahorse) puts these records into question. As the shipments were generally described as ivory carvings, teeth or trophies, and US Customs codes for seahorse species resemble those for hippopotamus, most of these records are probably erroneous (Brian Giles, in litteris, 7 December 2003).

Hong Kong SAR did not record any imports from Tanzania between the onset of seahorse trade recording in January 1998 and December 2002. However, Hong Kong Customs records do show that $1.68 \mathrm{t}$ of dried seahorses purportedly originating in Tanzania were re-exported from Hong Kong SAR to mainland China in August 1999, worth HK\$242000 (US\$30976) in total (Census and Statistics Department Hong Kong, unpublished data). The gap in recorded imports from Tanzania may arise partly from importers' lack of familiarity with new declarations for seahorses and partly because seahorses initially entered Hong Kong SAR in small shipments: anything transported in personal luggage, postal packages valued at less than HK\$4000 (US\$512) or sent as a gift was exempt from customs declaration (Boris Kwan, in litteris, 28 September 2000). Of the two export traders interviewed in Tanzania, one sent his seahorse shipments by courier and the other said his clients transported them in personal luggage. Hong Kong Customs records, therefore, lend credence to the fact that dried seahorse exports from Tanzania were substantial and suggest that they exceeded the $634-937 \mathrm{~kg}$ inferred in this study.

\section{East African seahorse conservation}

Although neither Kenya nor Tanzania had any specific measures in place to protect seahorses in 2000 , efforts in both countries to restrict minimum mesh sizes, phase out destructive fishing practices and regulate trawling potentially benefited these fish. Furthermore, respondents suggested that seahorses occurred in a number of the region's marine parks and reserves.

Unfortunately, enforcement of fishing regulations was often poor, as Fisheries officers in both countries readily admitted. In Kenya, for example, trawling vessels - officially restricted to waters further than 5 miles offshore - were known to operate as close as 2 miles from shore. In Tanzania, Fisheries officials disagreed over whether beach seining, a major source of seahorse bycatch, was banned outright or only when mesh sizes fell below a certain size. The practice remained widespread in 2000, particularly in Lindi District and Bagamoyo (personal observations).

Two Kenyan respondents suggested that seahorses were directly affected by coastal degradation. Destructive fishing techniques, high fishing pressure, pollution and mangrove cutting are known to have affected East Africa's marine environment, leading to reduced reef productivity (Moffat et al., 1998), declining catch per unit effort (Johnstone et al., 1998; Semesi et al., 1998), and substantially altered marine communities (McClanahan and KaundaArara, 1996). A resident of Watamu who regularly snorkelled in the area felt that seahorse abundance had declined locally since the 1980s because of mangrove logging and the concomitant loss of breeding habitats. A former ornamental fish dealer commented that seahorses once occurred in Port Reitz, Mombasa, but that the area was now devoid of fish because of pollution.

Few (24 of 234) respondents felt able to comment on the effects of bycatch or direct exploitation on seahorse abundance, and their comments were inconsistent and inconclusive. In Kenya, two fishers speculated that seahorses had declined over the past 20 years, but they offered no information to support their claims. An aquarium fish exporter, in contrast, felt confident that seahorse abundance in Kenya had not changed over this time period, based on her experience diving and collecting fish.

In Tanzania, eight fishers assumed that seahorse abundance had increased over the past 10-20 years because 'fish are always abundant' and small mesh sizes had been banned. In contrast, one fisher and one 
Fisheries official in Tanga, Tanzania, speculated that seahorse abundance had never fully recovered after the last El Niño event in 1997 had reduced seagrass habitats. Three other fishers and another Fisheries official stated that, in their experience, seahorse bycatch had remained stable over the past 10-20 years.

Among those involved in Tanzania's dried seahorse trade, three suggested that exploitation had no effect, basing their judgement on the number of seahorses caught or the availability of seahorse supplies. These respondents included a fisher (level 1) who had participated in a targeted seahorse fishery on Mafia Island in the early 1990s, a trader at Dar es Salaam's curio market (level 2-4), and one of two seahorse exporters (level 3-4) interviewed. Four other traders, however, raised concerns over the effects of exploitation:

- One major export trader (level 3-4) noted a marked decline in the availability of traded seahorses since 1975.

- A middle dealer (level 2-3) reportedly witnessed local seahorse catch plummet $85-90 \%$ in only three fortnights in response to the onset of seahorse exploitation in Mtambwe, Pemba, in 1996-1997. Although apparently drastic, such changes may reflect only local depletion or removal of more vulnerable cohorts, and need not necessarily reflect overall population declines (Hillborn and Walters, 1992).

- Two middle dealers (level 2-3), who traded primarily in Pemban seahorses, commented that large seahorses had become more difficult to obtain and the percentage of small seahorses in their supplies had increased.

The lack of consensus on declines should not lead to complacency. Although few in number, reports of problems could be early warning signs that wild populations are suffering, at least locally. Seahorse exploitation in Tanzania appeared to be patchy in space and time, due perhaps to the low financial incentive for fishers and the unpredictable timing of buyers' visits (at both low and high trade levels). Such patchiness may allow local seahorse populations to recover between bouts of exploitation. Interviewed traders, however, were entrepreneurial and seemed eager to expand their business if the opportunity arose. Close monitoring of future developments in the trade - best done in conjunction with research into local abundance and distribution of seahorse species - will be essential, therefore, to allow for timely conservation action as and when necessary. CITES will be an important tool in such monitoring, when fully implemented.

Because East African seahorses are mostly obtained as bycatch, regulation of export trade alone will not protect wild populations. Spatial and temporal restrictions in trawling and the use of other indiscriminate gear would be important contributions towards a multi-species and ecosystem approach to fisheries management. Effective enforcement of existing legislation regarding trawling, beach seining and minimum mesh sizes would, therefore, assist in moves towards precautionary management of seahorses, their habitats and other marine resources. Furthermore, all fishers should return bycatch to the water unharmed whenever possible, as is already commonly the case. An awareness campaign, potentially accompanied by the provision of working gloves to protect fishers sorting live bycatch from sharp teeth and poisonous spines, would benefit seahorses and many other marine animals in unwanted catch.

This paper is a contribution to the nascent body of knowledge about unconventional fisheries, their trades and their conservation implications. Much more such study is urgently needed to substantiate the real economic and ecological significance of small-scale fisheries and commerce. Unconventional fisheries, such as those supplying the trade in live food fish, marine curios, marine aquarium species and marine medicinals, remain poorly documented. Unlike conventional (dead food) fisheries, they are not monitored by the United Nations' Food and Agriculture Organization (Sadovy and Vincent, 2002), and reliable quantitative information on catch and trade volumes is sparse. Studies aimed at investigating the impact on wild populations are rare and generally conducted over short periods and small spatial scales (Sadovy and Vincent, 2002; Lunn and Moreau, in press). Two economic traits of unconventional fisheries, however, suggest that they may be prone to overexploitation: (1) opportunity costs for fishers are low, because they 
have few alternative sources of income; and (2) the value per unit catch tends to rise as the target species becomes rarer. Both factors render biological overfishing more likely, because the fishery will seem economically viable even as the resource heads towards collapse (Sadovy and Vincent, 2002). Groupers represent a possible example: in Southeast Asia, capture of groupers for the live food fishery is estimated to exceed sustainable yield, and there are many tales of local depletion (Sadovy and Vincent, 2002). In the marine aquarium fishery, concerns have been raised over size and sex-selective fishing (e.g. of the mandarinfish), heavy exploitation of naturally rare species or those with a limited geographic range (e.g. the Banggai cardinalfish), and the impact on non-target organisms whose symbionts are exploited (e.g. clients of cleaner wrasses) (Wabnitz et al., 2003).

On the bright side, unconventional fisheries have the potential to provide much-needed incomes to fishing communities in the developing world. The high economic value of many species in these trades encourages their exploitation on the one hand, but can also provide artisanal fishers with an incentive to manage their resources carefully, so as to ensure future supply.

The recent landmark decision to include seahorses in CITES Appendix II represents the first time that any fully marine commercially important fish has been listed. This sets a precedent, to the extent that two shark species, previously rejected, proposals on listing were reintroduced after the seahorse vote and were also accepted. Such support from CITES gives recognition to the fact that fishes are indeed 'wildlife' and that the sustainable exploitation of marine life may benefit from international scrutiny and cooperation.

\section{ACKNOWLEDGEMENTS}

This is a contribution from Project Seahorse. The research was made possible by a grant from the New England Biolabs Foundation and support from the John G. Shedd Aquarium (USA). Special thanks to the field assistant, Summit Johnstone Oketch, for his perseverance, to Claudie Senay and staff at the Canadian High Commission in Nairobi for their care and support, and to IUCN East Africa and the representatives of TRAFFIC in Nairobi and Dar es Salaam for their assistance. Our gratitude also extends to all informants for their patience and hospitality, with particular thanks to Jason Rubens, Catherine and Mafia Marine Park staff for providing a home and logistical support on Mafia Island. References provided by Marie-Annick Moreau, Sarah Foster and Melissa Grey were much appreciated, and we would like to thank Duncan McPherson, Jan Strugnell, John Baxter and an anonymous referee for their helpful comments on earlier drafts of this paper.

\section{REFERENCES}

Bell EM, Lockyear JF, McPherson JM, Marsden AD, Vincent ACJ. 2003. First field studies of an endangered South African seahorse, Hippocampus capensis. Environmental Biology of Fishes 67: 35-46.

Choo CK, Liew HC. 2003. Spatial distribution, substrate assemblages and size composition of sea horses (Family Syngnathidae) in the coastal waters of Peninsular Malaysia. Journal of the Marine Biological Association of the United Kingdom 83: 271-276.

CITES. 2002a. Twelfth Meeting of the Conference of the Parties: Comments from the Parties and Comments and Recommendations from the Secretariat on the Proposals to Amend Appendices I and II. http://www.cites.org/eng/cop/ $12 /$ prop/sec_rec.shtml (accessed 16 April 2004).

CITES. 2002b. Web Notice: Amendments to Appendices I and II of the Convention. http://www.cites.org/common/cop/ 12/appendix_notice.PDF (accessed 16 April 2004).

Foster SJ, Vincent ACJ. In press. The life history and ecology of seahorses, Hippocampus spp.: implications for conservation and management. Journal of Fish Biology.

Golani D, Fine M. 2002. On the occurrence of Hippocampus fuscus in the eastern Mediterranean. Journal of Fish Biology 60: 764-766.

Hillborn R, Walters CJ. 1992. Quantitative Fisheries Stock Assessment. Chapman and Hall: New York.

IUCN 2003. 2003 IUCN Red List of Threatened Species. IUCN, Gland, Switzerland. http://www.redlist.org/ (accessed 17 April 2004). 
Johnstone RW, Muhando CA, Francis J. 1998. The status of the coral reefs of Zanzibar: one example of a regional predicament. Ambio 27: 700-707.

Kuiter RH. 2000. Seahorses, Pipefishes and their Relatives: A Comprehensive Guide to Syngnathiformes. TMC Publishing: Chorleywood, UK.

Kuiter RH. 2001. Revision of the Australian seahorses of the genus Hippocampus (Syngnathioformes: Syngnathidae) with a description of nine new species. Records of the Australian Museum 53: 293-340.

Kuiter RH, Debelius H. 1994. Southeast Asia Tropical Fish Guide. IKAN-Unterwasserarchiv: Frankfurt, Germany.

Lourie SA, Randall JE. 2003. A new pygmy seahorse, Hippocampus denise (Teleostei: Syngnathidae), from the IndoPacific. Zoological Studies 42: 284-291.

Lourie SA, Vincent ACJ, Hall HJ. 1999. Seahorses: An Identification Guide to the World's Species and their Conservation. Project Seahorse: London.

Lowe RT. 1843. Lophobranchiae, Syngnathidae. In A History of the Fishes of Madeira. Bernard Quaritch: London; $6-12$.

Lunn K, Moreau M-A. In press. Unmonitored trade in marine ornamental fishes: the case of the Banggai cardinalfish (Pterapogon kauderni). Coral Reefs.

Marshall NT. 1998. Searching for a Cure: Conservation of Medicinal Wildlife Resources in East and Southern Africa. TRAFFIC International: Cambridge.

McClanahan TR, KaundaArara B. 1996. Fishery recovery in a coral-reef marine park and its effect on the adjacent fishery. Conservation Biology 10: 1187-1199.

Moffat D, Ngoile MN, Linden O, Francis J. 1998. The reality of the stomach: coastal management at the local level in eastern Africa. Ambio 27: 590-598.

Ping A. 1999. From proletarian internationalism to mutual development: China's cooperation with Tanzania, 1965-95. In Agencies in Foreign Aid: Comparing China, Sweden and the United States in Tanzania, Hyden G, Mukandala R (eds). MacMillan Press: London; 156-201.

Sadovy YJ, Vincent ACJ. 2002. Ecological issues and the trades in live reef fishes. In Coral Reef Fishes: Dynamics and Diversity in a Complex Ecosystem, Sale PF (ed.). Academic Press: Boston; 391-420.

Semesi AK, Mgaya YD, Muruke MHS, Francis J, Mtolera M, Msumi G. 1998. Coastal resources utilization and conservation issues in Bagamoyo, Tanzania. Ambio 27: 635-644.

Vincent ACJ. 1990. Reproductive ecology of seahorses. PhD thesis, University of Cambridge.

Vincent ACJ. 1996. The International Trade in Seahorses. TRAFFIC International: Cambridge.

Vincent ACJ, Sadler LM. 1995. Faithful pair bonds in wild seahorses, Hippocampus whitei. Animal Behaviour 50: $1557-1569$.

Wabnitz C, Taylor M, Green E, Razak T. 2003. From Ocean to Aquarium. UNEP-WCMC: Cambridge, UK. 